Article

\title{
Overexpression of the Aspergillus fumigatus Small GTPase, RsrA, Promotes Polarity Establishment during Germination
}

\author{
Adela Martin-Vicente, Ana C. O. Souza ${ }^{\circledR}$, Ashley V. Nywening, Wenbo Ge and \\ Jarrod R. Fortwendel * \\ Department of Clinical Pharmacy and Translational Science, University of Tennessee Health Science Center, \\ Memphis, TN 38163, USA; amartinv@uthsc.edu (A.M.-V.); aolivei5@uthsc.edu (A.C.O.S.); \\ ashnywe@uthsc.edu (A.V.N.); wge@uthsc.edu (W.G.) \\ * Correspondence: jfortwen@uthsc.edu; Tel.: +1-901-448-5140
}

Received: 6 October 2020; Accepted: 11 November 2020; Published: 13 November 2020

check for updates

\begin{abstract}
Cell polarization comprises highly controlled processes and occurs in most eukaryotic organisms. In yeast, the processes of budding, mating and filamentation require coordinated mechanisms leading to polarized growth. Filamentous fungi, such as Aspergillus fumigatus, are an extreme example of cell polarization, essential for both vegetative and pathogenic growth. A major regulator of polarized growth in yeast is the small GTPase Rsr1, which is essential for bud-site selection. Here, we show that deletion of the putative A. fumigatus ortholog, $r s r A$, causes only a modest reduction of growth rate and delay in germ tube emergence. In contrast, overexpression of $r s r A$ results in a morphogenesis defect, characterized by a significant delay in polarity establishment followed by the establishment of multiple growth axes. This aberrant phenotype is reversed when rsrA expression levels are decreased, suggesting that correct regulation of RsrA activity is crucial for accurate patterning of polarity establishment. Despite this finding, deletion or overexpression of $r s r A$ resulted in no changes of $A$. fumigatus virulence attributes in a mouse model of invasive aspergillosis. Additional mutational analyses revealed that RsrA cooperates genetically with the small GTPase, RasA, to support $A$. fumigatus viability.
\end{abstract}

Keywords: Rsr1; Ras; Aspergillus fumigatus; polarity establishment; germination

\section{Introduction}

Aspergillus fumigatus is the most common filamentous fungal pathogen in immunocompromised patients and is the causative agent of invasive infections associated with unacceptably high mortality rates [1]. In order to produce invasive infections, resting conidia of $A$. fumigatus must undergo a process of germination whereby the inhaled conidia break dormancy and initiate a highly polarized growth process. This polarized growth process focuses new cell wall and membrane material specifically to the germ tube apex, underpinning the development of hyphae that invade substrate material for nutrient acquisition. Conidial germination and hyphal growth are regulated in response both to extracellular and intracellular stimuli which activate signal transduction pathways that orchestrate the multi-complex polarity machinery by regulating the organization of the cytoskeleton, secretion and endocytosis, recruitment of cytoplasmic factors, and delivery of new membrane components to the polarity site [2]. The study of these molecular mechanisms in pathogenic filamentous organisms such as A. fumigatus is expected to deepen our understanding of invasive fungal infections and to potentially lead to the discovery of novel antifungal targets focused on blocking the initiation or halting the progression of tissue invasion. 
Signaling networks orchestrated by GTPase proteins are often described as major contributors to germination and polarized growth processes in fungi. As such, signaling pathways headed by members of the Ras superfamily are known to be important for many fungal cellular processes including polarity establishment, asexual and sexual development, stress responses and virulence [3]. RasA is the major Ras sub-family GTPase in A. fumigatus and roles for RasA-driven networks in the pathogenic potential of this fungus have been previously studied by our group [4-12]. As with the majority of GTPase proteins, RasA activation is positively regulated by Guanine nucleotide Exchange Factors (GEFs), which promote the release of guanosine diphosphate (GDP)-bound GTPases, and negatively regulated by GTPase Activating Proteins (GAPs), which stimulate the intrinsic GTPase activity of these proteins [13]. We recently uncovered a genetic interaction between two RasGEF proteins, GefA and GefB, showing that deletion of both RasGEFs produced a synthetic lethal phenotype in A. fumigatus [12]. Although GefA appears to be a direct regulator of RasA in A. fumigatus, GefB shares a higher level of homology with Bud5p, a RasGEF that regulates the activity of Rsr1p in the model yeast Saccharomyces cerevisiae $[12,14,15]$.

Rsr1 functions have been extensively studied in budding yeast, but little information is available about the function of this GTPase in filamentous fungi. Several studies in S. cerevisiae have shown that the Rsr1 GTPase module, formed by Rsr1p together with its activator (Bud5p) and its inactivator (Bud2p), is crucial for correct bud-site selection [15-22]. During yeast cell division, cortical landmark proteins promote localized activation of Rsr1p by Bud5p, which initiates recruitment of the polarization machinery components to the incipient bud site. Rsr1p activation drives the concentration of GTP-Cdc42p at the bud site membrane and subsequently results in symmetry breaking, characterized by a switch from isotropic growth to growth along a polarized axis [19,23-28]. Several studies in S. cerevisiae have demonstrated that, although Rsr1p itself has no effect on growth rate, deletion or overexpression of Rsr1 causes randomization of the selection of budding sites. Therefore, Rsr1p is essential for normal bud site patterns but not for polarity maintenance or bud formation [16,17]. Similar results are observed in the human pathogen Candida albicans. However, in contrast to S. cerevisiae, the Rsr1 GTPase module contributes to hyphal tip morphogenesis in C. albicans by regulating the distribution of Cdc42 at hyphal tips [29]. A CaRsr1 deletion strain has a random bud site selection pattern but also shows abnormal yeast and hyphal cell morphology, abnormal number of hyphal branches, and loss of viability at $42{ }^{\circ} \mathrm{C}$ [30].

In filamentous fungi, where cytokinesis does not result in the complete separation of mother and daughter cells, the role of Rsr1 is still largely unclear. In Ashbya gossypii, a fungus closely related to budding yeast, AgRsr1 is important for normal hyphal growth rate, morphogenesis and polarity maintenance. Disruption of this gene causes mislocalization of an important component of the polarisome, Spa2, and this translates into significantly reduced growth rates due to frequent phases of pausing at the hyphal tips, atypical morphology and development of aberrant branching sites [31]. In the filamentous fungus model organism Neurospora crassa, disruption of the ScRsr1 homolog, Krev-1, does not affect conidial germination, hyphal growth rates or morphology. However, mutants with constitutively active Krev-1 display an inhibition in the development of perithecia, suggesting that this gene is important for sexual cycle progression [32].

Here, we explore roles for the Rsr1 ortholog, RsrA, in hyphal growth and germination of A. fumigatus. Whereas deletion of $r s r A$ resulted in reduced growth and germination rates accompanied by normal hyphal morphology, overexpression of $r s r A$ caused increased instances of polarity establishment sites during germination. Despite this finding, neither loss- nor gain-of-function RsrA mutations altered the virulence potential of A. fumigatus. We also report that, similar to our earlier studies with the putative RasA and RsrA GEF proteins, GefA and GefB, double deletion of the putative downstream GTPases, RasA and RsrA, is synthetically lethal. 


\section{Materials and Methods}

\subsection{Strains and Growth Conditions}

The A. fumigatus strains used in this study are listed in Table 1. All strains were cultured in Glucose Minimum Medium (GMM) agar [33] plus uridine/uracil, when necessary, and incubated at $30{ }^{\circ} \mathrm{C}$ or $37^{\circ} \mathrm{C}$ for $4-7$ days. To assess fungal morphology, strains were cultured in filtered GMM broth for $14-18 \mathrm{~h}$ at $30^{\circ} \mathrm{C}$ or $37^{\circ} \mathrm{C}$. To culture strains for genomic DNA or total RNA extraction, GMM was supplemented with $0.5 \%$ yeast extract (GMM-YE) in order to potentiate growth. GMM supplemented with 1.2 M sorbitol (Sorbitol Minimum Medium (SMM)) was utilized after fungal transformations, to allow the protoplasts to recover properly.

Table 1. Strains used in this study.

\begin{tabular}{|c|c|c|}
\hline Strain & Genetic Background & Source or Reference \\
\hline KU80 $\Delta p y r G$ & CEA17 & Fungal Genetics Stock Center [34] \\
\hline$\Delta a k u B-p y r G^{+}$ & KU80 $\Delta p y r G$ & [11] \\
\hline$\Delta r s r A$ & KU80 spyrG & This study \\
\hline$\Delta r s r A+$ GFP-rsr $A$ & $\Delta r s r A$ & This study \\
\hline$P_{h s p A^{-}-r s r A}$ & $\Delta a k u B-p y r G^{+}$ & This study \\
\hline TetOn-ras $A$ & $\Delta a k u B-p y r G^{+}$ & This study \\
\hline$\Delta r s r A / p T e t O n-r a s A$ & $\Delta r s r A$ & This study \\
\hline$\Delta r a s A$ & $\Delta a k u B-p y r G^{+}$ & This study \\
\hline$\Delta r s r A+$ GFP-rsr $A / \Delta r a s A$ & $\Delta r s r A+\mathrm{GFP}-r s r A$ & This study \\
\hline
\end{tabular}

\subsection{Analysis of Growth and Germination Rates}

To determine if RsrA is important for A. fumigatus growth, five microliters containing $10^{4}$ conidia were inoculated in the center of GMM agar plates and incubated at $37^{\circ} \mathrm{C}$, and diameters were measured every day for a $96 \mathrm{~h}$ period. Pictures were taken at the end of day 4 . For germination assays, four thousand conidia were inoculated in GMM broth and at least five hundred conidia were counted every hour. The presence of a germ tube was considered to be the endpoint to define establishment of polarity. The involvement of RsrA in germ tube emergence orientation was also evaluated. To do this, conidia were incubated in GMM at $37^{\circ} \mathrm{C}$ until two germ tubes were observed and the germlings were scored for right/acute $\left(\leq 90^{\circ}\right)$ or obtuse $\left(>90^{\circ}\right)$ angle of germ tube orientation. Three biological replicates were performed for each analysis, and data are presented as mean \pm standard deviation.

\subsection{Stress Analyses}

To determine potential roles for RsrA in response to osmotic, membrane and cell wall stresses, spot dilution assays were performed. Briefly, suspensions of 10 to $10^{4}$ conidia were inoculated in GMM supplemented with $1 \mathrm{M} \mathrm{NaCl}, 1 \mathrm{M} \mathrm{KCl}, 1.2 \mathrm{M}$ sorbitol, $0.0125 \%$ SDS, Congo Red (40 and $80 \mu \mathrm{g} / \mathrm{mL}$ ) or Calcofluor White $(40$ and $80 \mu \mathrm{g} / \mathrm{mL})$. Agar plates were incubated at $37^{\circ} \mathrm{C}$ for $72 \mathrm{~h}$. To evaluate susceptibility to oxidative stress, GMM agar plates were inoculated with $1 \times 10^{7}$ conidia and allowed to dry. Then, a section of the center of the agar was excised and filled with $50 \mu \mathrm{L}$ of a solution of $200 \mathrm{mM}$ $\mathrm{H}_{2} \mathrm{O}_{2}$. Inhibition zone diameters were measured after $24 \mathrm{~h}$ at $37^{\circ} \mathrm{C}$. Caspofungin Minimal Effective Concentration (MEC) and voriconazole Minimum Inhibitory Concentration (MIC) were determined at 24 and 48 h, respectively, as recommended in the CLSI M38 document (CLSI 2017). All analyses were performed in triplicates, and data are represented as mean \pm standard deviation. 


\subsection{Genetic Manipulations}

The $r s r A$ deletion mutant was generated by replacing the complete $r s r A$ Open Reading Frame (ORF) by the Aspergillus parasiticus pyrG cassette [35] in the A. fumigatus KU80 $\Delta$ pyrG genetic background [34]. This strain is unable to grow in the absence of uridine/uracil, because it is deficient in orotidine $5^{\prime}$-monophosphate decarboxylase activity. Therefore, the resulting $r s r A$ deletion is pyrimidine prototrophic. Protoplast generation and transformation were performed as previously described [36] and colonies able to grow in media lacking uridine/uracil were genotyped by multiple PCRs of genomic DNA.

For complementation of the deletion mutant, $r s r A$ was ectopically expressed under the control of its native promoter and tagged with Green Fluorescent Protein (GFP) at the N-terminus for subsequent localization studies, using our CRISPR-Cas9 technique [37]. Briefly, the $r s r A$ coding sequence and approximately $1 \mathrm{~kb}$ of the $r s r A$ promoter were cloned into plasmid pAGRP, which contains enhanced GFP (eGFP) and a phleomycin resistance cassette [5]. The repair template for CRISPR/Cas9-based integration was amplified from the modified pAGRP and contained $35 \mathrm{bp}$ regions of microhomology targeting either side of protospacer adjacent motifs (PAMs) both up- and downstream of the non-functional A. fumigatus pyrG locus, as previously described [12].

To decipher subcellular localization of RsrA in the absence of RasA, a ras $A$ deletion was generated in the $\Delta r s r A+$ GFP-rsrA strain as well as in the $\triangle a k u B-p y r G^{+}$control strain. Briefly, two PAMs were first chosen, one upstream and one downstream of the ras $A$ coding sequence, to direct Cas9-induced double strand breaks and mediate repair template integration, as we have previously described [37]. A hygromycin resistance repair template was amplified from plasmid pJMR2 [38] and utilized in a CRISPR/Cas9-mediated transformation to replace the entire ras $A$ locus, generating a complete gene deletion [37].

Two mutant strains with regulatable ras $A$ expression were generated by replacing the ras $A$ native promoter with the tetracycline-inducible pTetOn promoter in both the $\triangle a k u B-p y r G^{+}$and $\triangle r s r A$ genetic backgrounds. A repair template containing a phleomycin resistance gene followed by the TetOn cassette was amplified from the plasmid pCH008-phleo to contain $35 \mathrm{bp}$ regions of microhomology to the ras $\mathrm{A}$ promoter region immediately upstream of the ras $A$ transcriptional start, as recently performed [12]. Protoplasts were plated on SMM supplemented with $62 \mu \mathrm{g} / \mathrm{mL}$ of phleomycin and $30 \mu \mathrm{g} / \mathrm{mL}$ of doxycycline. Further PCR analyses were used to confirm the correct promoter replacement.

For $r s r A$ overexpression, the endogenous $r s r A$ promoter was replaced by the A. fumigatus heat shock protein $\mathrm{A}(h s p A)$ promoter in the $\triangle a k u B-p y r G^{+}$genetic background [39]. Briefly, a repair template containing a hygromycin resistance cassette followed by the $h s p A$ promoter was amplified from plasmid pJMR2 [38] and contained microhomology regions homologous to the promoter region of $r s r A$. In this case, a PAM site was chosen in the position -4 bp relative to the $r s r A$ start codon.

All transformations were performed as previously described [37] and hygromycin- or phleomycin-resistant colonies were screened and genotyped by multiple PCRs to confirm a precise homologous integration.

\subsection{Fluorescence Microscopy}

To analyze the GFP-rsr A strains for RsrA subcellular localization, $10^{3}$ conidia were inoculated onto sterile coverslips in $5 \mathrm{~mL}$ of GMM and incubated in static culture at $37^{\circ} \mathrm{C}$ for $14 \mathrm{~h}$. The coverslips were then washed with distilled water and GFP fluorescence was analyzed using a Nikon Ni-U fluorescence microscope equipped with a Nikon DS-Qi1 Mc camera using a GFP filter. Images were captured using Nikon Elements software (v. 4.0). Images were then processed using the Nikon Elements AR Analysis 2-D Deconvolution software on Automatic settings. To assess the effect of cytochalasin A, $10^{3}$ conidia from both control and $\Delta r s r A+$ GFP-rsrA strains were grown as described above. After $14 \mathrm{~h}$, the medium was removed and replaced with fresh media containing $10 \mu \mathrm{g} / \mathrm{mL}$ of the anti-actin agent and incubated for two additional hours. The strains were finally observed under a fluorescence microscope, as described above. 


\subsection{RNA Extraction and $R T-q P C R$}

For RNA extraction, $5 \times 10^{7}$ conidia were inoculated in GMM-YE and grown for $18 \mathrm{~h}$ at $30^{\circ} \mathrm{C}$ or $37^{\circ} \mathrm{C}$ with agitation at $250 \mathrm{rpm}$. After this time, the mycelia were washed with distilled water and crushed with liquid nitrogen. The powdered samples were resuspended in $1 \mathrm{~mL}$ of Trizol (Invitrogen ${ }^{\mathrm{TM}}$, Waltham, MA, USA) and incubated on ice for $5 \mathrm{~min}$. Afterwards, $0.2 \mathrm{~mL}$ of chloroform-isoamyl alcohol (24:1) were added, followed by $3 \mathrm{~min}$ on ice. After centrifugation of $15 \mathrm{~min}$ at 13,000 rpm, the clear aqueous phase was mixed with an equal volume of ice-cold $70 \%$ ethanol and the RNA extraction was continued using an RNAeasy kit (Qiagen, Germantown, MD, USA). Six micrograms of RNA were treated with Turbo DNAase (Invitrogen, Carlsbad, CA, USA) following the manufacturer's instructions. Five hundred nanograms of RNA were retrotranscribed using the ProtoScript II cDNA synthesis kit (New England Biolabs, Ipswich, MA, USA) and the resulting cDNA was treated with RNAase $\mathrm{H}$ (New England Biolabs, Ipswich, MA, USA) for $20 \mathrm{~min}$ at $37^{\circ} \mathrm{C}$ to remove any remaining RNA traces. RT-qPCR was performed in $20 \mu \mathrm{L}$ PCR reactions in a CFX Connect Real-Time System (Bio-Rad, Hercules, CA, USA) using SYBR ${ }^{\circledR}$ Green Master Mix (Bio-Rad, Hercules, CA, USA). The conditions were as follows: $95^{\circ} \mathrm{C}$ for $3 \mathrm{~min}$, followed by 40 cycles of $10 \mathrm{~s}$ at $95^{\circ} \mathrm{C}, 15 \mathrm{~s}$ at $55^{\circ} \mathrm{C}$ and $45 \mathrm{~s}$ at $72{ }^{\circ} \mathrm{C}$. A melting curve analysis was carried out immediately after PCR completion to check specificity of the amplification. Primers specific for RsrA and $\beta$-tubulin A (TubA) were designed to flank introns. Cycle threshold $(\mathrm{Ct})$ values for RsrA were normalized to those of the housekeeping TubA and the relative expression was determined using the $2^{-\Delta \mathrm{Ct}}$ and $2^{-\Delta \Delta \mathrm{Ct}}$ methods [40]. Each analysis was performed in technical and biological triplicates.

\subsection{Murine Model of Invasive Pulmonary Aspergillosis}

Six-week-old CD-1 female mice (Charles River, Wilmington, MA, USA), weighing approximately $25 \mathrm{~g}$, were immunosuppressed intraperitoneally with $150 \mathrm{mg} / \mathrm{kg}$ of cyclophosphamide starting 3 days before the infection and on days 1,4 and 7 post-inoculation. In addition, a single injection of triamcinolone acetonide (Kenalog, Bristol-Myers Squibb, Princeton, NJ, USA) was administered subcutaneously the day before the inoculation. On day 0 , the mice were slightly anesthetized with isoflurane and challenged with $10^{6}$ conidia suspended in saline solution, by nasal instillation. The animals were monitored at least twice a day for a period of two weeks and those showing severe signs of disease were humanely euthanized by anoxia with $\mathrm{CO}_{2}$. In order to prevent bacterial infections, mice were given a mixture of sulfamethoxazole and trimethoprim in their drinking water, starting 3 days before the infection. Survival curves were compared using the log-rank test in GraphPad Prism v. 8.2.1 for Windows. The studies were performed in accordance with the approved protocol (project identification code: 19-0067.0, date of approval: 07/2020) by the Institutional Animal Care and Use committee of the University of Tennessee Health Science Center.

\section{Results}

\subsection{RsrA Regulates Growth and Polarity Establishment in A. fumigatus}

To identify an A. fumigatus homolog of the S. cerevisiae RsrA protein, a BLAST search was performed against the A. fumigatus Af293 genome (FungiDB; Genome Version 2015-09-27) using the S. cerevisiae protein sequence from the Saccharomyces genome database. The protein putatively encoded by Afu5g08950 shares a predicted amino acid sequence identity of $55.56 \%$ with the S. cerevisiae RsrAp. This putative protein is 210 amino acids in length and encodes an Ras effector domain as well as GTP/GDP binding domains and a CAAX box (Figure S1). We have therefore named this putative A. fumigatus protein RsrA. A notable difference between the yeast and A. fumigatus RsrA sequences is found in the length of the hypervariable region, with the A. fumigatus RsrA region being shorter (Figure S1). This finding is similar to previously reported differences in the hypervariable regions of A. fumigatus RasA and S. cerevisiae Ras2p [7]. 
To analyze the cellular functions of this small GTPase in A. fumigatus, we first generated a gene deletion strain and, to ensure that the resulting phenotypes were due to the specific deletion of $r s r A$, a complemented strain was also generated by ectopic integration of a GFP-fused $r s r A$ allele under the control of the native $r s r A$ promoter. This strain was referred to as $\triangle r s r A+$ GFP-rsr $A$. The strain $\triangle a k u B-p y r G^{+}$was used as a control for all the assays performed in this study [11].

When the macro-and micro-morphology of the control and $\Delta r s r A$ strains were analyzed, we observed no significant differences, suggesting that RsrA does not have an overt role in A. fumigatus hyphal morphogenesis (Figure S2). However, growth and germination (i.e., establishment of a polarized growth axis) rates in glucose minimal media (GMM) were impaired when the GTPase was deleted (Figure 1). We observed a statistically significant reduction of growth after 48,72 and $96 \mathrm{~h}$ of incubation in GMM agar at $37^{\circ} \mathrm{C}$ (Figure 1A,B). This reduction in growth was accompanied by a delay in the initiation of germination of approximately two hours (Figure $1 \mathrm{C}$ ). Five percent $( \pm 1 \%)$ of conidia from the control strain developed a germ tube after $5 \mathrm{~h}$ of incubation in $\mathrm{GMM}$ at $37^{\circ} \mathrm{C}$, whereas conidia of the deletion mutant initiated polarity establishment after $7 \mathrm{~h}$. Further, almost $90 \%(88 \pm 1.73 \%)$ of conidia from the control strain had germinated after $8 \mathrm{~h}$, whereas only $39 \%( \pm 4.6 \%)$ of conidia from $\triangle r s r A$ had formed a germ tube by this time point. To determine whether RsrA activity impacted the pattern of germ tube emergence, the isogenic strain set was cultured in GMM at $37^{\circ} \mathrm{C}$ until $100 \%$ of the germinating conidia had generated two germ tubes. Five hundred germlings from each strain were then scored for obtuse $\left(>90^{\circ}\right)$ or right/acute $\left(\leq 90^{\circ}\right)$ angles of orientation of the two initial germ tube events, as shown in the schematic representation in Figure 1D. After $12 \mathrm{~h}$ of growth at $37^{\circ} \mathrm{C}$, almost $100 \%$ of the wild type germlings had generated two germ tubes, whereas the $r s r A$ deletion mutant required two additional hours to obtain the same result. We observed that $95.4 \%( \pm 1.8)$ of control and $94 \%( \pm 2.3)$ of $\triangle r s r A$ germlings formed germ tubes at $>90^{\circ}$ angle, and $4.6 \%$ and $6 \%$ formed germ tubes at $\leq 90^{\circ}$ angle, respectively (Figure 1D). Therefore, no significant differences were observed between strains. The complemented strain displayed equivalent colony diamaters and patterns of germination as the control strain (Figure 1), indicating that the phenotypes observed were due to the deletion of $r s r A$.

To identify potential roles for RsrA in A. fumigatus stress responses, $\triangle r s r A$ was also subjected to diverse external stressors, including: cell wall stress, using calcofluor white and congo red, compounds that target chitin and glucans, respectively; osmotic stress, using $\mathrm{NaCl}, \mathrm{KCl}$ and sorbitol; and oxidative stress employing hydrogen peroxide, in a spot dilution assay. When subjected to cell wall and oxidative stresses, the $\triangle r s r A$ mutant displayed growth similar to the control and complemented strains (Figure S3A). However, a slight increase in susceptibility of the knockout strain was observed in the presence of osmotic stress driven by $\mathrm{NaCl}$ or $\mathrm{KCl}$, but not in sorbitol, and surprisingly, this phenotype was only partially restored in the complemented strain (Figure S3B). This partial complementation could be the result of interefence by the N-terminal GFP-tag or the transcriptional overexpression of $r s r A$, resulting in tagging $r s r A$ with GFP in comparison to the control strain (Figure S3C). Additionally, in vitro susceptibility testing to echinocandin and triazole class antifungals was performed. We observed a caspofungin MEC of $0.125 \mu \mathrm{g} / \mathrm{mL}$ and a voriconazole MIC of $0.25 \mu \mathrm{g} / \mathrm{mL}$ for control, $\Delta r s r A$ and complemented strains. Additional phenotypic screens included the evaluation of growth at different temperatures $\left(30,37\right.$ and $\left.42^{\circ} \mathrm{C}\right)$. However, no significant differences in growth or germination potential were observed (data not shown). 
A.

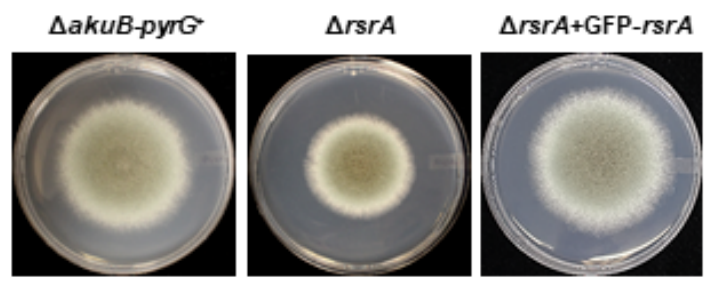

C.

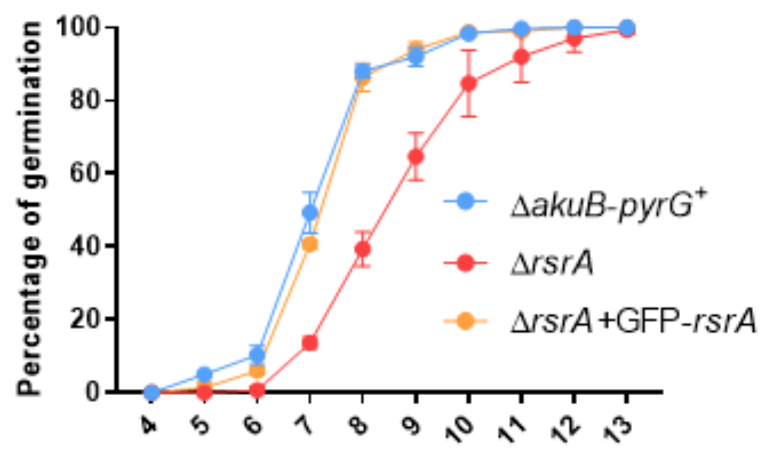

Time post-inoculation (hours)
B.

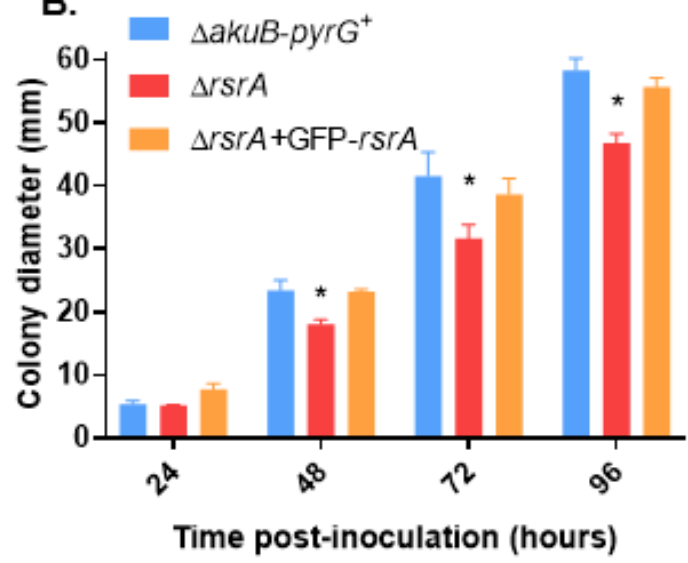

D.
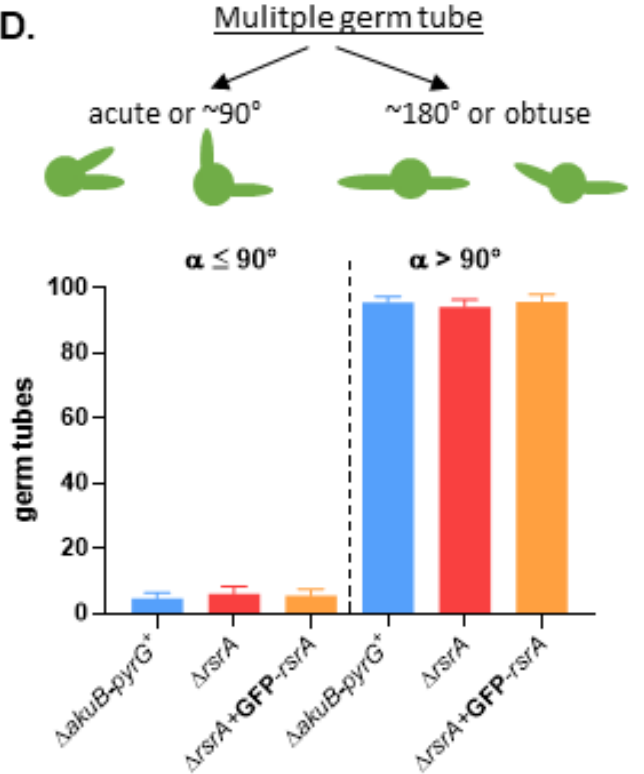

Figure 1. Deletion of $r s r A$ causes decreased colony development and delayed polarity establishment. (A) Colony morphology of the control $\left(\triangle a k u B-p y r G^{+}\right), r s r A$ deletion $(\triangle r s r A)$ and complemented $(\Delta r s r A+$ GFP-rsrA $)$ strains. Glucose Minimum Medium (GMM) agar plates were point-inoculated in the center of the plate with $5 \mu \mathrm{L}$ containing $10^{4}$ conidia and incubated at $37^{\circ} \mathrm{C}$ for $96 \mathrm{~h}$.(B) Colony diameters were measured every $24 \mathrm{~h}$ during a $96 \mathrm{~h}$ period. Diameters between strains were compared at each time point using 2-way ANOVA with Tukey's test for multiple comparisons (GraphPad Prism v. 8.2.1). Asterisks indicate a statistically significant difference (adjusted $p$ value $<0.0001$ ) between the $\triangle r s r A$ and both the control and the complemented strains at the indicated time point. (C) Ten thousand conidia were inoculated in GMM broth and incubated at $37^{\circ} \mathrm{C}$. The presence of a germ tube was considered to be the endpoint for polarity establishment, and percentage of germination was scored as the number of conidia producing a visible germ tube amongst 100 enumerated conidia. (D) Ten thousand conidia were allowed to grow in GMM at $37^{\circ} \mathrm{C}$ until two germ tubes were developed. Then, the orientation of the germ tubes was evaluated for at least 500 conidia and the number of conidia with germ tubes forming an acute/right, or an obtuse angle were quantified and compared between strains using one-way ANOVA. Measurements and error bars represent the mean and standard deviation of 3 independent experiments. 


\subsection{Overexpression of RsrA Alters the Spatial Regulation of Polarity Establishment}

When $r s r 1$ is overexpressed in budding yeast, dividing cells show the same random budding pattern as when the gene is deleted [16,17]. Therefore, we overexpressed $r s r A$ by replacing the endogenous promoter with $1000 \mathrm{bp}$ of the A. fumigatus Heat Shock Protein A ( $h s p A)$ promoter $\left(\mathrm{P}_{\mathrm{hspA}}\right)$, using a CRISPR-Cas9 gene targeting technique (Figure 2A). This promoter has been previously shown to drive high level expression of downstream genes in a temperature-dependent manner when used for ectopic gene expression [38,39]. Transcriptional profiling of the $\mathrm{P}_{\mathrm{hspA}}{ }^{-r s} \mathrm{r} A$ and control strains, analyzed by RT-qPCR at $30^{\circ} \mathrm{C}$ or $37^{\circ} \mathrm{C}$, revealed that expression of $r s r A$ was increased 22 -fold or 46-fold, respectively (Figure 2B). Germination assays at $37^{\circ} \mathrm{C}$ revealed that conidia of the A. fumigatus control strain started to establish polarity axes after $5 \mathrm{~h}$ of incubation in liquid GMM, and $100 \%$ of conidia had generated at least one germ tube within $12 \mathrm{~h}$ of culture (Figure 2C). However, high-level overexpression of $r s r A\left(37^{\circ} \mathrm{C}\right.$ culture) significantly delayed germination. Initial germ tube development in the $\mathrm{P}_{\text {hspA-rsr }} A$ mutant was only observed after $12 \mathrm{~h}$ of culture at $37^{\circ} \mathrm{C}$ and approximately $90 \%$ of conidia had germinated after $26 \mathrm{~h}$ (Figure 2C). At the end of $26 \mathrm{~h}$ of incubation at $37^{\circ} \mathrm{C}$, we also observed that $9.7 \%( \pm 0.6)$ of the $\mathrm{P}_{\mathrm{hspA}}-\mathrm{rs} r \mathrm{~A}$ conidia were only able to undergo the initial isotropic swelling phase of germination and did not establish a polarized growth axis. When $r s r A$ expression levels were decreased by reducing the culture temperature to $30{ }^{\circ} \mathrm{C}, 5.7 \%( \pm 1.5 \%)$ of the conidia from the control strain had generated the first germ tubes after $10 \mathrm{~h}$, whereas germination in the $r s r A$ overexpression strain was delayed by only one hour (Figure 2C). After $18 \mathrm{~h}$ of growth in GMM at $30^{\circ} \mathrm{C}$, $100 \%$ of conidia from the control strain and $97.7 \pm 1.52 \%$ of the $P_{\text {hspA }}-r s r A$ strain had successfully established polarity and generated at least one germ tube. Although high-level overexpression of $r s r A$ generated a significant polarity establishment defect, this delay in polarity establishment was not accompanied by a decreased colony diameter. On the contrary, an increase in the colony diameter after 72 and $96 \mathrm{~h}$ of growth in GMM at $37^{\circ} \mathrm{C}$ was observed for the $\mathrm{P}_{\mathrm{hspA}}-r s r A$ mutant (Figure 2D). These data suggested that, although initial polarity establishment is delayed, overexpression of $r s r A$ may promote rapid hyphal growth rate in A. fumigatus.

Notably, the $\mathrm{P}_{\mathrm{hspA}}-\mathrm{rsr} A$ strain also displayed an atypical micro-morphology. During early germination events at $37^{\circ} \mathrm{C}$, conidia from the control strain grew isotropically for 5-6 h, switching after this incubation period to polarized growth with only two polarized growth axes generated (Figure 3A). In contrast, conidia of the overexpression mutant exhibtied exaggerated swelling during the initial $12 \mathrm{~h}$ of culture, reaching a size of about $25 \mu \mathrm{m}$, approximately five times larger than swollen conidia of the control strain (Figure 3A). Once germinating conidia of the $\mathrm{P}_{\mathrm{hspA}}-r s r A$ mutant became competent for polarity establishment, a significantly increased number of polarity axes was noted within individual conidia (Figure 3A). The morphology of polarity establishment was strikingly different when the $\mathrm{P}_{\mathrm{hspA}}-\mathrm{rs} r \mathrm{~A}$ strain was cultured at $30^{\circ} \mathrm{C}$, displaying development of normal germination patterns and conidial morphology (Figure 3B). As shown in Figure 3B, after $14 \mathrm{~h}$ of incubation, the size of the swollen conidia from the $r s r A$ overexpression mutant appeared more similar to the control at $30^{\circ} \mathrm{C}$. In addition, only one germ tube was generated at a time and only two to three total germ tubes were produced by each germinating conidium. The control strain displayed the same morphology at both temperatures tested (Figure 3A,B). These results suggest that RsrA acts as a spatial regulator of polarity establishment and that accurate expression levels are essential to support normal germination patterns. 
A.

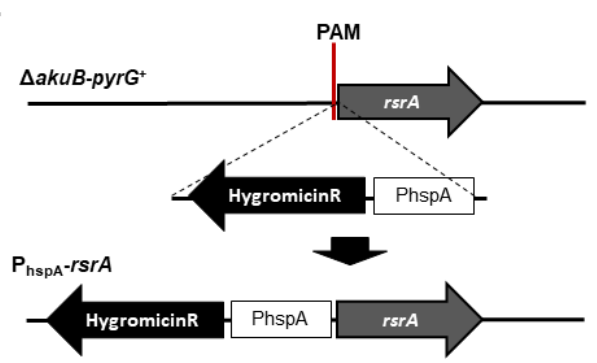

c.

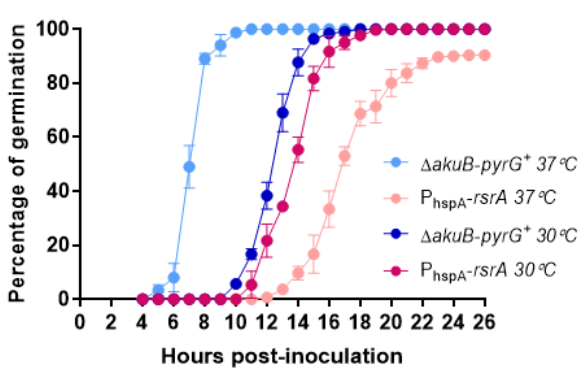

B.

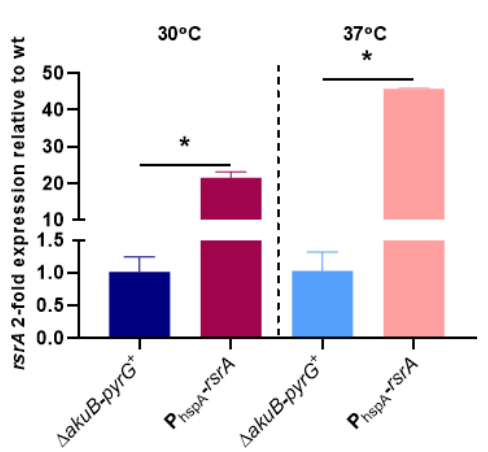

D.

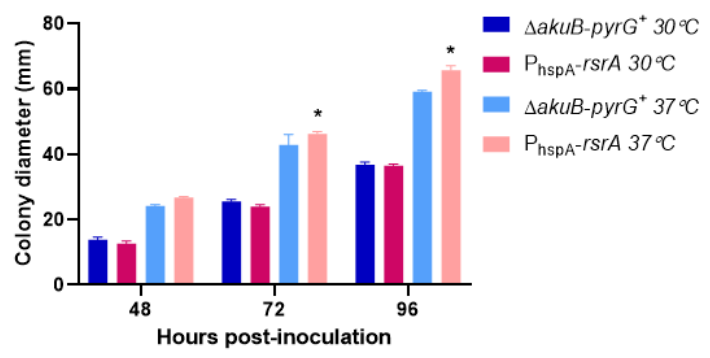

Figure 2. Overexpression of $r s r A$ causes a significant delay in polarity establishment. (A) Schematic representation of $r s r A$ promoter replacement by the constitutive Heat Shock Protein A ( $h s p A)$ promoter. A construct containing the hygromycin resistance cassette together with one thousand base pairs of the $h s p A$ promoter was used to target a Protospacer Adjacent Motif (PAM) in the $r s r A$ promoter. Arrows indicate the direction of gene transcription. (B) Expression of $r s r A$ was determined by RT-qPCR for both control and overexpressed $r s r A$ strains. Cycle threshold $(\mathrm{Ct})$ values of $r s r A$ were normalized to those of the endogenous standard $t u b A$. Statistical analysis was performed using unpaired, two-tailed, Student's t-test in GraphPad Prism v. 8.2.1 ( $p \leq 0.0024)$. (C) Polarity establishment is delayed $8 \mathrm{~h}$ when $r s r A$ is overexpressed. Germination rates of control strain expressing native and overexpressed $r s r A$ were determined as explained in Materials and Methods. (D) Overexpression of $r s r A$ causes an increase in growth rate at $37^{\circ} \mathrm{C}$. Ten thousand conidia were point inoculated in the center of a GMM agar plate and incubated at $30^{\circ} \mathrm{C}$ or $37^{\circ} \mathrm{C}$. Colony diameters were measured every $24 \mathrm{~h}$ for a $96 \mathrm{~h}$ period and compared among groups at each time point using 2-way ANOVA with Tukey's test for multiple comparisons (GraphPad Prism v. 8.2.1). Asterisks indicate a statistically significant difference (adjusted $p$ value $<0.0001)$ between the control and the $\mathrm{P}_{\mathrm{hspA}}-r s r A$ strains at the indicated time point. 
A. $37^{\circ} \mathrm{C}$
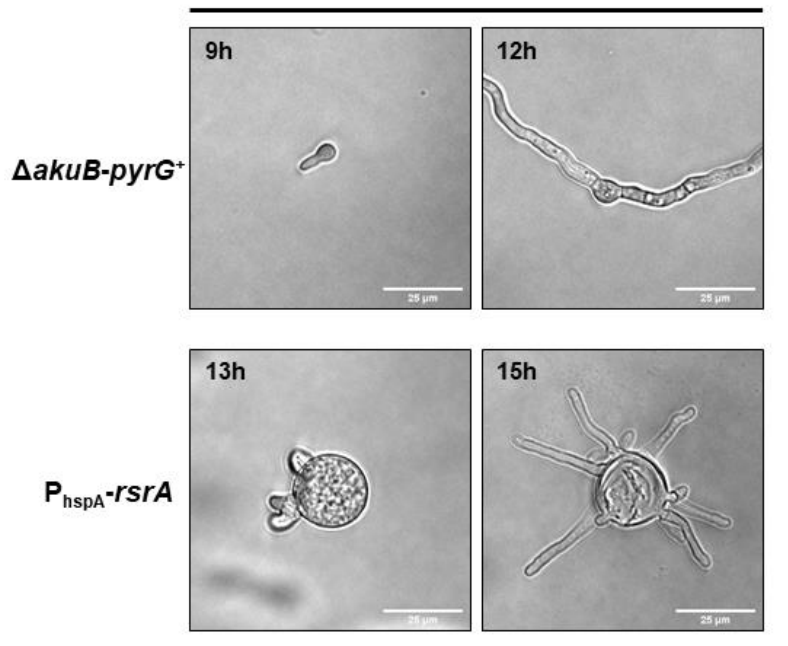

B.

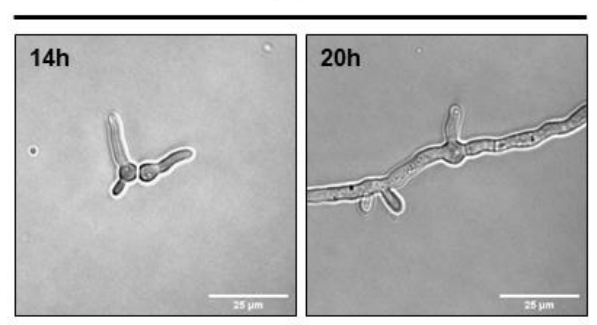

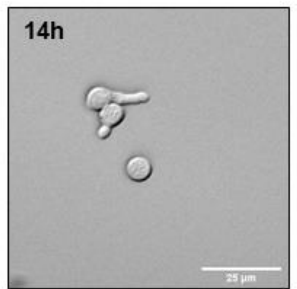

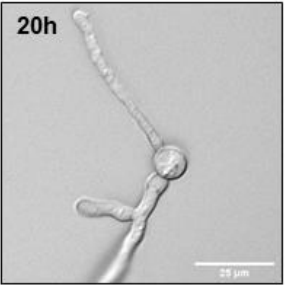

Figure 3. Overexpression of $r s r A$ produces a defect in patterning of polarity establishment. Depicted are time course microphotographs showing the development of control and $\mathrm{P}_{\mathrm{hspA}}-r s r A$ strains. Two thousand conidia were cultured in liquid GMM and incubated at $37^{\circ} \mathrm{C}(\mathbf{A})$ or $30^{\circ} \mathrm{C}(\mathbf{B})$ and microphotographs were taken at the indicated time points.

\subsection{A. fumigatus RsrA Localizes to Septa}

Previous studies have shown that, in S. cerevisiae, Rsr1p is widely distributed intracellularly but it is enriched at the plasma membrane and at sites of polarization [24]. Similarly, a GFP-AgRsr1p fusion protein localizes to the hyphal tip in A. gossypii [31]. As deletion and overexpression of $r s r A$ suggested a role in polarity establishment and hyphal growth rate, we next sought to determine the sub-cellular localization of RsrA in A. fumigatus using the $\Delta r s r A+$ GFP-rsrA complemented strain. Importantly, as evidenced by the phenotypic data outlined above, the strain expressing GFP-rsr $A$ was morphologically indistinguishable from the control strain, suggesting that the fusion protein is functional. During mature hyphal growth, the fluorescence pattern of GFP signal revealed that the GFP-rsrA chimeric protein was localized throughout the cytoplasm and was also concentrated at septa (Figure 4A). To see if localization of RsrA to septa was dependent on active actin polymerization, we employed treatment with cytochalasin A. This compound is an actin polymerization inhibitor that binds to actin filaments ends and, consequently, limits actin assembly [41]. The control and the $\Delta r s r A+$ GFP-rsrA strains were cultured for mature hyphal development in media lacking cytochalasin A, and then treated with the anti-actin agent for two additional hours of culture. As shown in Figure 4B, treatment with cytochalasin $\mathrm{A}$ was associated with a reduction in septum fluorescence and induced cytoplasmic mislocalization of RsrA (Figure 4B). Control experiments with DMSO did not show any detectable alteration when compared to the control without the solvent (Figure 4C). These results suggest that RsrA presence at the septum is dependent on an intact actin cytoskeleton. 
A.
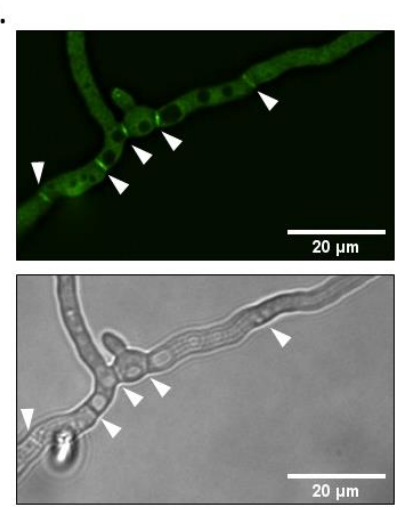

B.
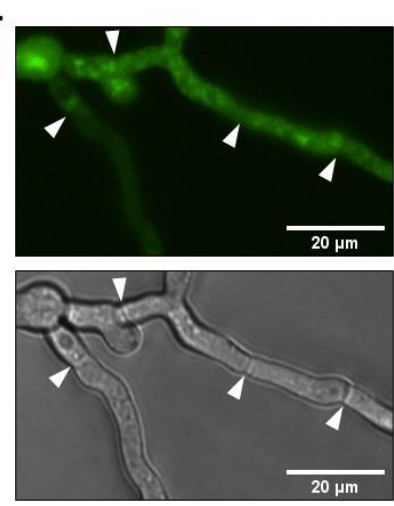

C.
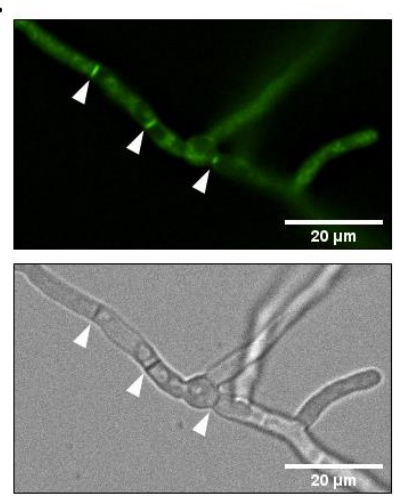

Figure 4. GFP-rsr $A$ is concentrated at septa in an actin-dependent fashion. (A) One thousand conidia of the $\Delta r s r A+$ GFP-rsrA strain were incubated in GMM broth for $14 \mathrm{~h}$ at $37^{\circ} \mathrm{C}$. B. GFP- $r s r A$ localization is actin-dependent. One thousand conidia were cultured in GMM for $14 \mathrm{~h}$ at $37^{\circ} \mathrm{C}$. The medium was then replaced by fresh GMM containing $10 \mu \mathrm{g} / \mathrm{mL}$ of cytochalasin A (B) or DMSO (C) and cultures were incubated for an additional $2 \mathrm{~h}$. Note that the addition of $2 \%$ DMSO had no effect on hyphal development or localization of GFP-rsrA. Microphotographs were taken with a Nikon X fluorescence microscope equipped with a GFP filter. White arrows indicate septa.

\subsection{RsrA Is Dispensable for A. fumigatus Virulence}

Because overexpression of $r s r A$ caused altered germination at host physiological temperatures, we next sought to determine whether our loss- or gain-of-function mutations would influence murine invasive pulmonary aspergillosis outcomes. In order to examine the impact of these polarity establishment defects on virulence, we used a chemotherapeutic murine model of invasive pulmonary aspergillosis, and virulence was assessed using survival as the endpoint. Regardless of experimental arm, animals started to succumb to the infection 4 days after the inoculation. We observed that neither deletion nor overexpression of $r s r A$ altered virulence of $A$. fumigatus (Figure 5). In fact, these strains caused an $87.5 \%$ ( 7 out of 8 mice) of mortality by day 8 post-infection, whereas $37.5 \%$ ( 3 out of 8 mice) of animals inoculated with the control strain were alive by the end of the experiment. However, no statistical differences were observed between survival curves. The median survival times for $\triangle a k u B$-pyrG $G^{+}, \Delta r s r A, \mathrm{P}_{\mathrm{hspA}}-r s r A$ and $\Delta r s r A+\mathrm{GFP}-r s r A$ groups were $5.5,6,5.5$ and 6.5 days, respectively. These results suggest that RsrA is not required for the ability of $A$. fumigatus to invade tissue and generate disease in the host.

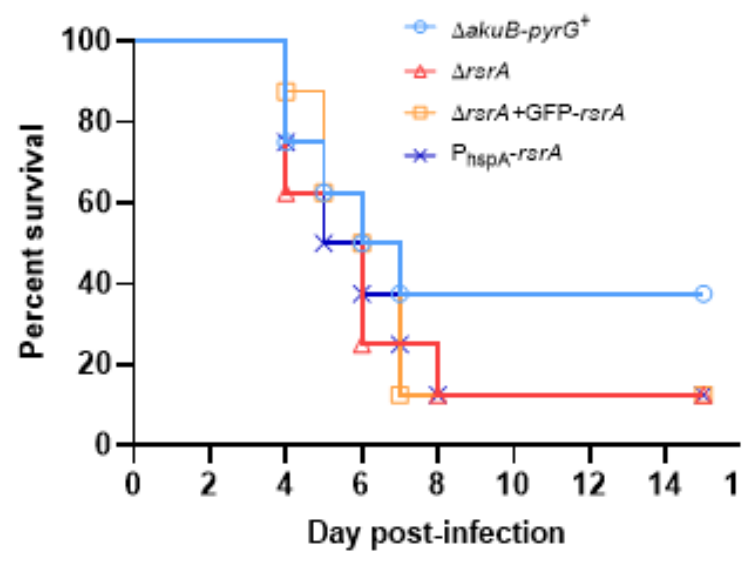

Figure 5. RsrA is not essential for the virulence of $A$. fumigatus. Survival curves of mice $(n=8)$ infected intranasally with $10^{6}$ conidia of control and $r s r A$ mutant strains. The Kaplan-Meier curves were compared using log rank tests in GraphPad Prism v. 8.2.1. No statistical differences were observed between experimental arms. 


\subsection{RsrA and RasA Interact Genetically to Control Polarity Establishment}

Previous studies in yeast have shown that the major Ras sub-family proteins, Ras1p/Ras2p, and Rsr1p have overlapping roles supporting viability, as the loss of Ras1/2p and Rsr1p activities in S. cerevisiae and Y. lypolitica is lethal $[42,43]$. To determine whether a similar relationship between RsrA and RasA pathways exists in filamentous fungi, we attempted to generate a double deletion mutant. Viable transformants were unobtainable after multiple attempts, suggesting that these pathways may share an overlapping role essential to A. fumigatus viability. To confirm this, we next constructed a strain with regulatable ras $A$ expression by replacing the ras $A$ promoter with the tetracycline-inducible TetOn promoter [44] in the $\triangle r s r A$ background. This new strain was referred to as $\triangle r s r A / p$ TetOn-ras $A$. To generate a reliable control strain confirming phenotypic results of repression of ras $A$ expression, we performed the same genetic modification in the control strain $\triangle a k u B-p y r G^{+}$(Figure 6A). This control strain was referred to as pTetOn-rasA. When culturing the pTetOn-ras A control strain on GMM in the absence of doxycycline, we observed the production of a compact colony morphology that was associated with stunted, swollen hyphae characteristic of the $\triangle$ ras $A$ strain reported previously (Figure 6B,C, Figure S4 and [6]). In contrast, in the presence of increasing doxycycline concentrations, the macroscopic colony phenotype of the pTetOn-ras $A$ mutant improved and was indistinguishable from that of the parental strain at $30 \mu \mathrm{g} / \mathrm{mL}$ doxycycline (Figure 6B). Hyphal morphology of pTetOn-ras $A$ in submerged GMM broth culture also improved in the presence of increasing doxycycline concentrations, with hyphae maintaining stable growth axes and resembling wild type growth at $60 \mu \mathrm{g} / \mathrm{mL}$ doxycycline (Figure 6C, top row panels, and Figure S4). Because the pTetOn-ras $A$ mutant phenocopied the $\triangle$ ras $A$ strain under non-inducing conditions (Figure S4), we concluded that effective suppression of ras $A$ expression was achieved in the absence of doxycycline. In contrast, when ras $A$ expression was suppressed in the $\triangle r s r A$ background ( $\triangle r s r A / \mathrm{pTetOn}-r a s A, 0 \mu \mathrm{g} / \mathrm{mL}$ doxycycline), the majority of the conidia underwent isotropic growth but were not able to establish polarity after $24 \mathrm{~h}$ of growth in GMM at $37^{\circ} \mathrm{C}$ (Figure 6C, bottom panels). Increasing concentrations of doxycycline overcame this growth defect by inducing normal polarity establishment rates and hyphal morphology (Figure 6C, bottom panels). Wild type morphology was generated by addition of $120 \mu \mathrm{g} / \mathrm{mL}$ doxycycline to the GMM broth culture. These results support the hypothesis that RsrA and RasA interact genetically during early growth events. 
A.

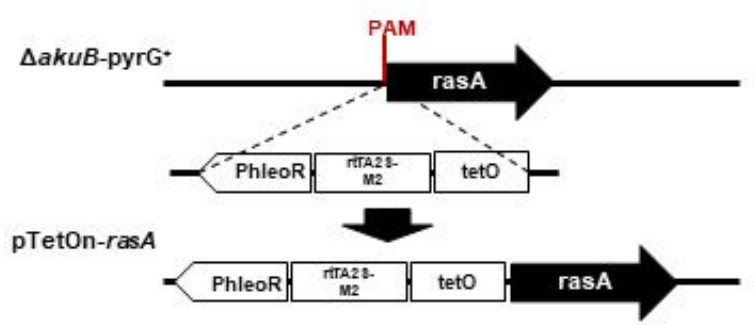

B.

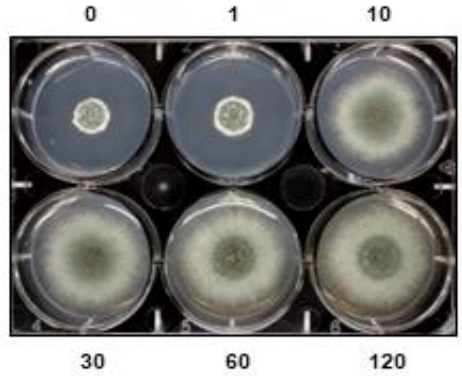

C.
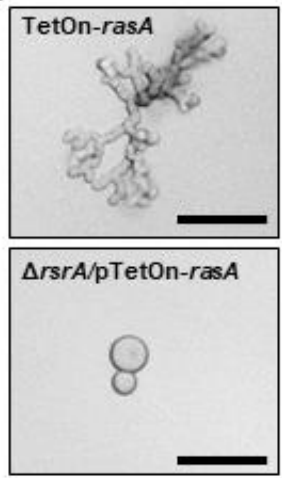

$\Delta$ rsrA/pTetOn-rasA
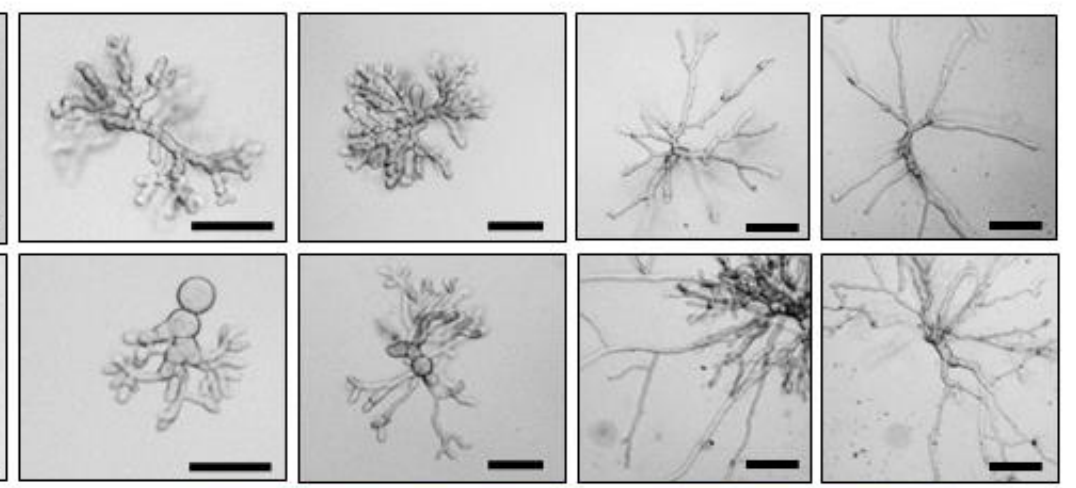

$0 \mu \mathrm{g} / \mathrm{ml}$

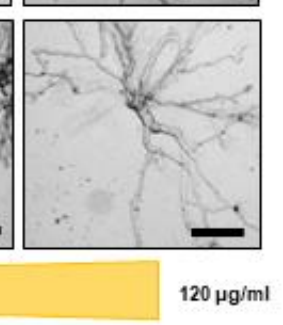

Doxycycline

Figure 6. Genetic interaction of RsrA and RasA during polarity establishment in A. fumigatus. (A) Schematic representation of $\operatorname{ras} A$ promoter replacement using the tetracycline-inducible promoter (rtTA-M2-TetO) to generate the TetOn-ras $A$ or $\triangle r s r A / p T e t O n-r a s A$ strains. (B) Ten thousand conidia from the TetOn-ras $A$ strain were point inoculated in the center of GMM agar plates containing $0-120 \mu \mathrm{g} / \mathrm{mL}$ of doxycycline. Photographs were taken after $72 \mathrm{~h}$ of growth at $37^{\circ} \mathrm{C}$. (C) Two thousand conidia from the TetOn-ras $A$ or the double mutant $\Delta r s r A / p$ TetOn-ras $A$ were inoculated in GMM broth with increasing concentrations of doxycycline and incubated at $37^{\circ} \mathrm{C}$ for $18 \mathrm{~h}$. In the absence of doxycycline, the TetOn-ras $A$ strain (upper panel) is indistinguishable from the ras $A$ knockout (Figure S4 and Fortwendel et al., 2008), while the double mutant (bottom panel) is unable to establish a polarity axis and produce viable hyphae. Proper hyphal morphologies are recovered at higher concentrations of doxycycline. Scale $=50 \mu \mathrm{M}$.

\subsection{RsrA Gene Expression, but Not Protein Localization, Is Dependent on RasA}

We have shown that RsrA localization at septa is actin-dependent and that RsrA and RasA genetically interact to orchestrate polarity establishment. Fungal Ras orthologs are also known to regulate the polarization of the actin cytoskeleton [45-51], therefore we next investigated whether RsrA localization in A. fumigatus might be dependent on the presence of RasA. To do this, we generated a complete deletion of the ras $A$ ORF in the background of the $\Delta r s r A+$ GFP-rsr $A$ strain. The resulting mutant strain displayed the same stunted colony and hyphal morphology as the ras $A$ deletion mutant. Although the morphology and phenotype of the RasA knockout has been well characterized in our laboratory [6], for better comparison purposes in the present study, we generated a ras $A$ deletion strain in the $\triangle a k u B-p y r G^{+}$genetic background that was completely identical to the $\triangle \operatorname{ras} A$ previously characterized by our group (Figure S4 and [6]).

As shown in Figure 7A and as described above, RsrA is localized throughout the cytoplasm and concentrated at septa in the $\triangle r s r A+$ GFP-rsr $A$ strain. When $r a s A$ was deleted in this genetic background $(\Delta r s r A+$ GFP-rsrA/ $\Delta r a s A)$, the GFP-rsrA signal remained at septa but also displayed an intense, diffuse cytoplasmic fluorescence when compared to a wild type background (Figure 7A). This surprising 
result suggested that GFP-rsrA presence might be increased when RasA activity is lost, likely either through increased $r s r A$ gene expression or stabilization of RsrA protein. To test whether $r s r A$ gene expression levels may be induced by the loss of $\operatorname{ras} A$, the expression of $r s r A$ was determined using RT-qPCR. Indeed, the $\Delta r s r A+$ GFP-rsr $A / \Delta r a s A$ strain expressed 2.5-fold more $r s r A$ than the parent $\Delta r s r A+$ GFP-rsrA strain (Figure 7B). Taken together, these findings suggest that RasA regulates RsrA at the level of gene transcription, and presumably, at the protein level for correct subcellular localization.

A.
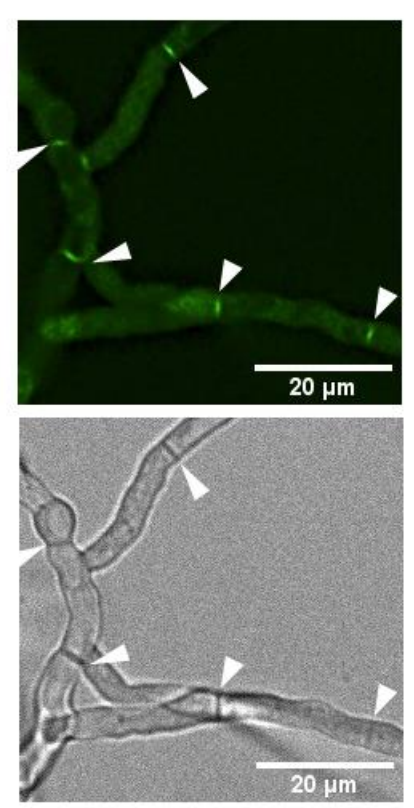

\section{$\Delta$ rsrA+GFP-rsrA/ArasA}
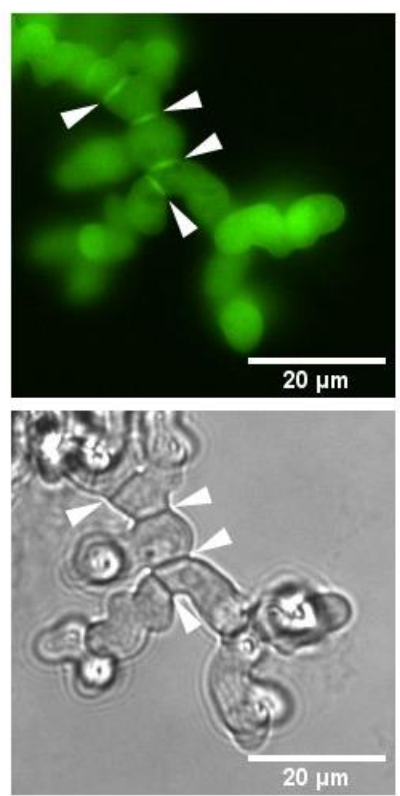

B.

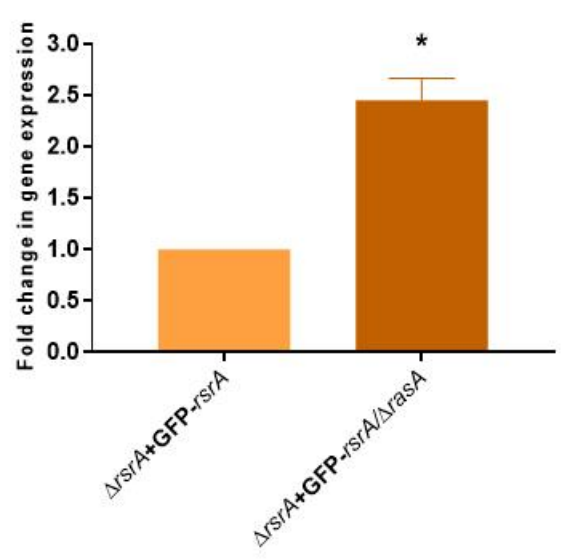

Figure 7. RasA regulates $r s r A$ expression, but not its cellular localization. (A) One thousand conidia from $\Delta r s r A+$ GFP-rsr $A$ or $\Delta r s r A+$ GFP-rsrA/ $\Delta r a s A$ strains were inoculated in liquid GMM and incubated at $37^{\circ} \mathrm{C}$ for $16 \mathrm{~h}$. Microphotographs were taken with a Nikon $X$ fluorescence microscope equipped with a GFP filter. (B) Deletion of ras $A$ causes an increase in $r s r A$ transcript levels. Expression of $r s r A$ in the $\Delta r s r A+$ GFP-rs $A / \Delta r a s A$ mutant relative to the parental $\Delta r s r A+$ GFP-rs $r A$ strain was determined by RT-qPCR using $A$. fumigatus $\beta$-tubulin $(t u b A)$ as the endogenous standard. Statistical analysis was performed using unpaired, two-tailed, Student's $t$-test in GraphPad Prism v. 8.2.1 for Windows $\left({ }^{*} p=0.0002\right.$ in comparison to the parental $\Delta r s r A+$ GFP-rs $r A$ strain). The experiment was performed in technical and biological triplicates. White arrows indicate septa.

\section{Discussion}

In this study, we report the characterization of the A. fumigatus RsrA small GTPase, orthologs of which are known mediators of polarized growth in yeast. However, our results surprisingly showed that RsrA is preferentially localized to the septum in A. fumigatus and not to the hyphal tip, as described for A. gossypii [31]. We found that the presence of this protein is non-essential for A. fumigatus growth, for the proper selection of growth axes during initial polarity establishment occurring after spore germination, or for normal branching patterns (Figure S2). In contrast, as overexpression of $r s r A$ resulted in aberrant germination phenotypes, we conclude that proper regulation of RsrA activity levels is likely necessary for spatiotemporal control of early events in A. fumigatus growth. The current study is only the third reported functional analysis of an Rsr1 ortholog in a monomorphic filamentous fungus, the previous two being for the Saccharomycete mold, A. gossypii, and for the Pezizomycotina mold, Neurospora crassa [31,32]. Whereas A. gossypii AgRsr1p guides directional hyphal growth via stabilization of the polarisome at the hyphal tip, mutation of the N. crassa Rsr1 ortholog, krev-1, produces no aberrant vegetative growth phenotypes [31,32]. Instead, the primary function of the Krev-1 
GTPase in N. crassa appears to be the regulation of sexual cycle progression [32]. Differences between basal phenotypes of Rsr1 ortholog mutants in these filamentous fungi show that, although the general GTPase modules may be conserved, their functional output varies.

Strikingly, the polarity establishment defects of the $r s r A$ overexpression mutant were only evident at high levels of over-expression, induced by host-physiological temperatures. Despite this finding, virulence in a murine model of invasive aspergillosis was unaltered by mutation of $\operatorname{rsr} A$. A previous study with $C$. albicans revealed that CaRsr1 is important for virulence in a gene-dose dependent manner. C. albicans is the only other human pathogenic fungus in which an Rsr1 ortholog has been studied. Whereas a heterozygote CaRSR1/Carsr1 strain was reported to cause $60 \%$ mortality, a homozygote disruptant strain was completely avirulent in a neutropenic murine model of disseminated candidiasis [52]. C. albicans is a pleomorphic yeast that grows in budding yeast, pseudohyphal and hyphal forms, and the transition of yeast-to-hyphae growth is a known virulence determinant. Disruption of CaRSR1 negatively impacts each of these growth forms, generating a mutant with reduced pathogenic fitness. Although $A$. fumigatus rsr $A$ overexpression did result in a temperature-sensitive germination defect, the pathogenic potential of the $\mathrm{P}_{\mathrm{hspA}}-\mathrm{rsr} A$ strain was likely maintained by the normal hyphal morphology and rapid growth rate of this mutant. Therefore, A. fumigatus RsrA signaling plays no overt role in tissue invasion and virulence.

Although overexpression of $r s r A$ resulted in a significant delay in the establishment of polarity, breaking of conidial dormancy during germination was not delayed. This fact was evidenced by the development of large, isotropically swollen conidia in this mutant. Interestingly, we reported a similar phenotype in a mutant strain expressing constitutively active RasA in A. fumigatus [7,9]. When RasA protein activity cannot be properly regulated due to the introduction of a point mutation that inhibits the RasA-RasGAP interaction, A. fumigatus conidia undergo a prolonged period of isotropic swelling before polarity is eventually established $[7,9]$. However, unlike the $r s r A$ overexpression strain, the pattern of germ tube emergence is not altered by constitutively active RasA [7,9]. Nevertheless, these results suggest co-regulation of RasA and RsrA pathways wherein activity of both RasA and RsrA must increase for the efficient breaking of spore dormancy and then be properly downregulated for the correct timing of polarity establishment. However, RsrA also plays a separate role in the spatial positioning of new growth axes during initial polarity establishment. Previous studies in yeast revealed a genetic interaction between these signaling pathways, as disruption of Ras1, Ras2 and Rsr1 results in inviability [42]. In the yeast Yarrowia lipolytica, deletion of Rsr1 in cells lacking Ras1 also results in lethality [43]. As with yeast, we found loss of both $r s r A$ and $r a s A$ to be synthetically lethal and, in A. fumigatus, this lethality is likely due to the inability of the double mutant to establish a polarized growth axis. In addition, we have revealed novel links between these pathways in $A$. fumigatus, as loss of RasA caused both increased expression of $r s r A$ while not affecting the localization of RsrA to septa.

The precise mechanism underlying how RsrA- and RasA-driven pathways work in concert to orchestrate the early events in A. fumigatus growth are still under investigation. Several studies have demonstrated that the Rsr1 GTPase module interacts genetically and physically with Cdc42 and its regulators to organize the actin cytoskeleton and septin filaments to the selected site of polarized growth in yeast $[16,19,23,25,26,28,53-55]$. Active Rsr1 recruits the GEF, Cdc24, to accomplish Cdc42 activation at the incipient bud site in yeast [23,54]. Cyclical inactivation of Rsr1 results in Cdc42 release, ensuring the integrity of yeast phase growth is maintained. For organisms such as C. neoformans, in which an Rsr1 ortholog does not exist, Ras proteins have been posited to play an analogous role by interacting with Cdc24 when activated and, in turn, recruiting and activating Cdc42 [56]. Previous studies in not only C. neoformans, but in multiple other fungi, have also shown that Ras cooperates with the highly conserved Rho-GTPase Cdc42 to control actin cytoskeleton polarization during growth and differentiation [17,49-51,57-60]. Cdc42 is highly conserved in the eukaryotic kingdom and represents an essential component of the polarisome in both yeast and filamentous fungi. In A. fumigatus and other ascomycete molds, both Rsr1 and Ras orthologs exist. Taken together, our previously published and current data support the hypothesis that, at least for A. fumigatus, RasA 
may signal to the Cdc42 module through Rsr1-dependent mechanisms for polarity establishment and through Rsr1-independent pathways for hyphal morphogenesis. Testing this hypothesis will be the focus of future studies.

In summary, the data presented here suggest that, as with S. cerevisiae Rsr1, A. fumigatus RsrA likely functions as an internal polarity cue for polarized growth, but that this role is largely restricted to initial polarity establishment events during germination. A continued role for polarity maintenance in terms of hyphal growth guidance is less apparent in A. fumigatus, as hyphal morphogenesis of the $r s r A$ mutants generated here is not significantly altered.

Supplementary Materials: The following are available online at http://www.mdpi.com/2309-608X/6/4/285/s1, Figure S1: Sequence alignment of Rsr1 from Saccharomyces cerevisiae and Aspergillus fumigatus, Figure S2: Deletion of $r s r A$ does not affect hyphal morphology in A. fumigatus, Figure S3: Loss of $r s r A$ does not increase susceptibility to oxidative, membrane or cell wall stress, Figure S4: The micromorphology of the control strain $\triangle a k u B-p y r G^{+}$, $\triangle r s r A$ and $\triangle r a s A$ is not altered by doxycycline treatment.

Author Contributions: Conceptualization, A.M.-V. and J.R.F.; Formal analysis, A.M.-V. and J.R.F.; Funding acquisition, J.R.F.; Investigation, A.M.-V., A.C.O.S., A.V.N., W.G. and J.R.F.; Methodology, A.M.-V.; Supervision, J.R.F.; Visualization, A.M.-V. and J.R.F.; Writing—original draft, A.M.-V. and J.R.F.; Writing—review and editing, A.M.-V., A.C.O.S., A.V.N., W.G. and J.R.F. All authors have read and agreed to the published version of the manuscript.

Funding: This research was funded by The National Institutes of Health, grant numbers R01AI106925 and R01AI143197.

Conflicts of Interest: The funders had no role in the design of the study; in the collection, analyses, or interpretation of data; in the writing of the manuscript, or in the decision to publish the results.

\section{References}

1. Brown, G.D.; Denning, D.W.; Gow, N.A.R.; Levitz, S.M.; Netea, M.G.; White, T.C. Hidden killers: Human fungal infections. Sci. Transl. Med. 2012, 4, 165rv113. [CrossRef] [PubMed]

2. Drubin, D.G.; Nelson, W.J. Origins of cell polarity. Cell 1996, 84, 335-344. [CrossRef]

3. Fortwendel, J.R. Orchestration of morphogenesis in filamentous fungi: Conserved roles for Ras signaling networks. Fungal Biol. Rev. 2015, 29, 54-62. [CrossRef] [PubMed]

4. Fortwendel, J.R. Ras-mediated signal transduction and virulence in human pathogenic fungi. Fungal Genom. Biol. 2012, 2, 105. [CrossRef] [PubMed]

5. Fortwendel, J.R.; Juvvadi, P.R.; Rogg, L.E.; Asfaw, Y.G.; Burns, K.A.; Randell, S.H.; Steinbach, W.J. Plasma membrane localization is required for RasA-mediated polarized morphogenesis and virulence of Aspergillus fumigatus. Eukaryot. Cell 2012, 11, 966-977. [CrossRef]

6. Fortwendel, J.R.; Fuller, K.K.; Stephens, T.J.; Bacon, W.C.; Askew, D.S.; Rhodes, J.C. Aspergillus fumigatus RasA regulates asexual development and cell wall integrity. Eukaryot. Cell 2008, 7, 1530-1539. [CrossRef]

7. Fortwendel, J.R.; Panepinto, J.C.; Seitz, A.E.; Askew, D.S.; Rhodes, J.C. Aspergillus fumigatus ras A and rasB regulate the timing and morphology of asexual development. Fungal Genet. Biol. 2004, 41, 129-139. [CrossRef]

8. Fortwendel, J.R.; Juvvadi, P.R.; Pinchai, N.; Perfect, B.Z.; Alspaugh, J.A.; Perfect, J.R.; Steinbach, W.J. Differential effects of inhibiting chitin and 1,3-\{beta\}-D-glucan synthesis in ras and calcineurin mutants of Aspergillus fumigatus. Antimicrob. Agents Chemother. 2009, 53, 476-482. [CrossRef]

9. Fortwendel, J.R.; Juvvadi, P.R.; Rogg, L.E.; Steinbach, W.J. Regulatable Ras activity is critical for proper establishment and maintenance of polarity in Aspergillus fumigatus. Eukaryot. Cell 2011, 10, 611-615. [CrossRef]

10. Al Abdallah, Q.; Norton, T.S.; Hill, A.M.; LeClaire, L.L.; Fortwendel, J.R. A fungus-specific protein domain is essential for RasA-mediated morphogenetic signaling in Aspergillus fumigatus. mSphere 2016, 1, e00234-16. [CrossRef]

11. Al Abdallah, Q.; Martin-Vicente, A.; Souza, A.C.O.; Ge, W.; Fortwendel, J.R. C-terminus proteolysis and palmitoylation cooperate for optimal plasma membrane localization of RasA in Aspergillus fumigatus. Front. Microbiol. 2018, 9, 562. [CrossRef] [PubMed] 
12. Martin-Vicente, A.; Souza, A.C.O.; Al Abdallah, Q.; Ge, W.; Fortwendel, J.R. SH3-class Ras guanine nucleotide exchange factors are essential for Aspergillus fumigatus invasive growth. Cell Microbiol. 2019, 21, e13013. [CrossRef]

13. Boguski, M.S.; McCormick, F. Proteins regulating Ras and its relatives. Nature 1993, 366, 643-654. [CrossRef] [PubMed]

14. Van Dam, T.J.; Rehmann, H.; Bos, J.L.; Snel, B. Phylogeny of the CDC25 homology domain reveals rapid differentiation of Ras pathways between early animals and fungi. Cell Signal 2009, 21, 1579-1585. [CrossRef] [PubMed]

15. Bender, A. Genetic evidence for the roles of the bud-site-selection genes BUD5 and BUD2 in control of the Rsr1p (Bud1p) GTPase in yeast. Proc. Natl. Acad. Sci. USA 1993, 90, 9926-9929. [CrossRef] [PubMed]

16. Bender, A.; Pringle, J.R. Multicopy suppression of the cdc24 budding defect in yeast by CDC42 and three newly identified genes including the ras-related gene RSR1. Proc. Natl. Acad. Sci. USA 1989, 86, 9976-9980. [CrossRef]

17. Ruggieri, R.; Bender, A.; Matsui, Y.; Powers, S.; Takai, Y.; Pringle, J.R.; Matsumoto, K. RSR1, a ras-like gene homologous to Krev-1 (smg21A/rap1A): Role in the development of cell polarity and interactions with the Ras pathway in Saccharomyces cerevisiae. Mol. Cell Biol. 1992, 12, 758-766. [CrossRef]

18. Park, H.-O.; Chant, J.; Herskowitz, I. BUD2 encodes a GTPase-activating protein for Budl/Rsrl necessary for proper bud-site selection in yeast. Nature 1993, 365, 269-274. [CrossRef] [PubMed]

19. Kang, P.J.; Beven, L.; Hariharan, S.; Park, H.-O. The Rsr1/Bud1 GTPase interacts with itself and the Cdc42 GTPase during bud-site selection and polarity establishment in budding yeast. Mol. Biol. Cell 2010, 21, 3007-3016. [CrossRef]

20. Park, H.-O.; Sanson, A.; Herskowitz, I. Localization of Bud2p, a GTPase-activating protein necessary for programming cell polarity in yeast to the presumptive bud site. Genes Dev. 1999, 13, 1912-1917. [CrossRef]

21. Kang, P.J.; Sanson, A.; Lee, B.; Park, H.-O. A GDP/GTP exchange factor involved in linking a spatial landmark to cell polarity. Science 2001, 292, 1376-1378. [CrossRef] [PubMed]

22. Chant, J.; Herskowitz, I. Genetic control of bud site selection in yeast by a set of gene products that constitute a morphogenetic pathway. Cell 1991, 65, 1203-1212. [CrossRef]

23. Park, H.-O.; Bi, E.; Pringle, J.R.; Herskowitz, I. Two active states of the Ras-related Bud1/Rsr1 protein bind to different effectors to determine yeast cell polarity. Proc. Natl. Acad. Sci. USA 1997, 94, 4463-4468. [CrossRef] [PubMed]

24. Park, H.-O.; Kang, P.J.; Rachfal, A.W. Localization of the Rsr1/Bud1 GTPase involved in selection of a proper growth site in yeast. J. Biol. Chem. 2002, 277, 26721-26724. [CrossRef]

25. Kang, P.J.; Miller, K.E.; Guegueniat, J.; Beven, L.; Park, H.-O. The shared role of the Rsr1 GTPase and Gic1/Gic2 in Cdc42 polarization. Mol. Biol. Cell 2018, 29, 2359-2369. [CrossRef]

26. Kozminski, K.G.; Beven, L.; Angerman, E.; Tong, A.H.; Boone, C.; Park, H.-O. Interaction between a Ras and a Rho GTPase couples selection of a growth site to the development of cell polarity in yeast. Mol. Biol. Cell 2003, 14, 4958-4970. [CrossRef]

27. Lee, M.E.; Lo, W.C.; Miller, K.E.; Chou, C.S.; Park, H.-O. Regulation of Cdc42 polarization by the Rsr1 GTPase and Rga1, a Cdc42 GTPase-activating protein, in budding yeast. J. Cell Sci. 2015, 128, 2106-2117. [CrossRef]

28. Miller, K.E.; Lo, W.-C.; Chou, C.-S.; Park, H.-O. Temporal regulation of cell polarity via the interaction of the Ras GTPase Rsr1 and the scaffold protein Bem1. Mol. Biol. Cell 2019, 30, 2543-2557. [CrossRef]

29. Pulver, R.; Heisel, T.; Gonia, S.; Robins, R.; Norton, J.; Haynes, P.; Gale, C.A. Rsr1 focuses Cdc42 activity at hyphal tips and promotes maintenance of hyphal development in Candida albicans. Eukaryot. Cell 2013, 12, 482-495. [CrossRef]

30. Hausauer, D.L.; Gerami-Nejad, M.; Kistler-Anderson, C.; Gale, C.A. Hyphal guidance and invasive growth in Candida albicans require the Ras-like GTPase Rsr1p and its GTPase-activating protein Bud2p. Eukaryot. Cell 2005, 4, 1273-1286. [CrossRef]

31. Bauer, Y.; Knechtle, P.; Wendland, J.; Helfer, H.; Philippsen, P. A Ras-like GTPase is involved in hyphal growth guidance in the filamentous fungus Ashbya gossypii. Mol. Biol. Cell 2004, 15, 4622-4632. [CrossRef] [PubMed]

32. Ito, S.; Matsui, Y.; Toh-E, A.; Harashima, T.; Inoue, H. Isolation and characterization of the krev-1 gene, a novel member of ras superfamily in Neurospora crassa: Involvement in sexual cycle progression. Mol. Gen. Genet. 1997, 255, 429-437. [CrossRef] 
33. Shimizu, K.; Keller, N.P. Genetic involvement of a cAMP-dependent protein kinase in a G protein signaling pathway regulating morphological and chemical transitions in Aspergillus nidulans. Genetics 2001, 157, 591-600. [PubMed]

34. Da Silva Ferreira, M.E.; Kress, M.R.V.Z.; Savoldi, M.; Goldman, M.H.S.; Hartl, A.; Heinekamp, T.; Brakhage, A.A.; Goldman, G.H. The akuBKU80 mutant deficient for nonhomologous end joining is a powerful tool for analyzing pathogenicity in Aspergillus fumigatus. Eukaryot. Cell 2006, 5, 207-211. [CrossRef] [PubMed]

35. Calvo, A.M.; Bok, J.; Brooks, W.; Keller, N.P. veA is required for toxin and sclerotial production in Aspergillus parasiticus. Appl. Environ. Microbiol. 2004, 70, 4733-4739. [CrossRef]

36. Yelton, M.M.; Hamer, J.E.; Timberlake, W.E. Transformation of Aspergillus nidulans by using a trpC plasmid. Proc. Natl. Acad. Sci. USA 1984, 81, 1470-1474. [CrossRef] [PubMed]

37. Al Abdallah, Q.; Ge, W.; Fortwendel, J.R. A simple and universal system for gene manipulation in Aspergillus fumigatus: In vitro-assembled Cas9-Guide RNA ribonucleoproteins coupled with microhomology repair templates. mSphere 2017, 2, e00446-17. [CrossRef]

38. Rybak, J.M.; Ge, W.; Wiederhold, N.P.; Parker, J.E.; Kelly, S.L.; Rogers, P.D.; Fortwendel, J.R. Mutations in hmg1, challenging the paradigm of clinical triazole resistance in Aspergillus fumigatus. mBio 2019, 10, 00437-19. [CrossRef]

39. Paul, S.; Klutts, J.S.; Moye-Rowley, W.S. Analysis of Promoter function in Aspergillus fumigatus. Eukaryot. Cell 2012, 11, 1167-1177. [CrossRef]

40. Livak, K.J.; Schmittgen, T.D. Analysis of relative gene expression data using real-time quantitative PCR and the $2^{-\Delta \Delta C T}$ method. Methods 2001, 25, 402-408. [CrossRef]

41. Brown, S.S.; Spudich, J.A. Mechanism of action of cytochalasin: Evidence that it binds to actin filament ends. J. Cell Biol. 1981, 88, 487-491. [CrossRef]

42. Morishita, T.; Mitsuzawa, H.; Nakafuku, M.; Nakamura, S.; Hattori, S.; Anraku, Y. Requirement of Saccharomyces cerevisiae Ras for completion of mitosis. Science 1995, 270, 1213-1215. [CrossRef] [PubMed]

43. Li, Y.Q.; Li, M.; Zhao, X.F.; Gao, X.D. A role for the rap GTPase YlRsr1 in cellular morphogenesis and the involvement of YlRsr1 and the ras GTPase YlRas2 in bud site selection in the dimorphic yeast Yarrowia lipolytica. Eukaryot. Cell 2014, 13, 580-590. [CrossRef] [PubMed]

44. Helmschrott, C.; Sasse, A.; Samantaray, S.; Krappmann, S.; Wagener, J. Upgrading fungal gene expression on demand: Improved systems for doxycycline-dependent silencing in Aspergillus fumigatus. Appl. Environ. Microbiol. 2013, 79, 1751-1754. [CrossRef] [PubMed]

45. Pichová, A.; Vondráková, D.; Breitenbach, M. Mutants in the Saccharomyces cerevisiae RAS2 gene influence life span, cytoskeleton, and regulation of mitosis. Can. J. Microbiol. 1997, 43, 774-781. [CrossRef] [PubMed]

46. Waugh, M.S.; Nichols, C.B.; DeCesare, C.M.; Cox, G.M.; Heitman, J.; Alspaugh, J.A. Ras1 and Ras2 contribute shared and unique roles in physiology and virulence of Cryptococcus neoformans. Microbiology 2002, 148, 191-201. [CrossRef]

47. Harispe, L.; Portela, C.; Scazzocchio, C.; Peñalva, M.A.; Gorfinkiel, L. Ras GTPase-activating protein regulation of actin cytoskeleton and hyphal polarity in Aspergillus nidulans. Eukaryot. Cell 2008, 7, 141-153. [CrossRef]

48. Fukui, Y.; Kozasa, T.; Kaziro, Y.; Takeda, T.; Yamamoto, M. Role of a ras homolog in the life cycle of Schizosaccharomyces pombe. Cell 1986, 44, 329-336. [CrossRef]

49. Boyce, K.J.; Hynes, M.J.; Andrianopoulos, A. The Ras and Rho GTPases genetically interact to co-ordinately regulate cell polarity during development in Penicillium marneffei. Mol. Microbiol. 2005, 55, 1487-1501. [CrossRef]

50. Ballou, E.R.; Kozubowski, L.; Nichols, C.B.; Alspaugh, J.A. Ras1 acts through duplicated Cdc42 and Rac proteins to regulate morphogenesis and pathogenesis in the human fungal pathogen Cryptococcus neoformans. PLoS Genet. 2013, 9, e1003687. [CrossRef]

51. Mosch, H.U.; Roberts, R.L.; Fink, G.R. Ras2 signals via the Cdc42/Ste20/mitogen-activated protein kinase module to induce filamentous growth in Saccharomyces cerevisiae. Proc. Natl. Acad. Sci. USA 1996, 93, 5352-5356. [CrossRef] [PubMed]

52. Yaar, L.; Mevarech, M.; Koltint, Y. A Candida albicans RAS-related gene (CaRSRl) is involved in budding, cell morphogenesis and hypha development. Microbiology 1997, 143, 3033-3044. [CrossRef] [PubMed] 
53. Chant, J.; Corrado, K.; Pringle, J.R.; Herskowitz, I. Yeast BUD5, encoding a putative GDP-GTP exchange factor, is necessary for bud site selection and interacts with bud formation gene BEM1. Cell 1991, 65, 1213-1224. [CrossRef]

54. Zheng, Y.; Bender, A.; Cerione, R.A. Interactions among proteins involved in bud-site selection and bud-site assembly in Saccharomyces cerevisiae. J. Biol. Chem. 1995, 270, 626-630. [CrossRef] [PubMed]

55. Shimada, Y.; Wiget, P.; Gulli, M.-P.; Bi, E.; Peter, M. The nucleotide exchange factor Cdc24p may be regulated by auto-inhibition. EMBO J. 2004, 23, 1051-1062. [CrossRef]

56. Nichols, C.B.; Perfect, Z.H.; Alspaugh, J.A. A Ras1-Cdc24 signal transduction pathway mediates thermotolerance in the fungal pathogen Cryptococcus neoformans. Mol. Microbiol. 2007, 63, 1118-1130. [CrossRef] [PubMed]

57. Quadri, R.; Galli, M.; Galati, E.; Rotondo, G.; Gallo, G.R.; Panigada, D.; Plevani, P.; Muzi-Falconi, M. Haspin regulates Ras localization to promote Cdc24-driven mitotic depolarization. Cell Discov. 2020, 6, 42. [CrossRef]

58. Nozaki, S.; Furuya, K.; Niki, H. The Ras1-Cdc42 pathway is involved in hyphal development of Schizosaccharomyces japonicus. FEMS Yeast Res. 2018, 18, 4. [CrossRef]

59. Chang, E.C.; Barr, M.; Wang, Y.; Jung, V.; Xu, H.P.; Wigler, M.H. Cooperative interaction of S. pombe proteins required for mating and morphogenesis. Cell 1994, 79, 131-141. [CrossRef]

60. Chen, C.; Ha, Y.-S.; Min, J.-Y.; Memmott, S.D.; Dickman, M.B. Cdc42 is required for proper growth and development in the fungal pathogen Colletotrichum trifolii. Eukaryot. Cell 2006, 5, 155-166. [CrossRef]

Publisher's Note: MDPI stays neutral with regard to jurisdictional claims in published maps and institutional affiliations.

(C) 2020 by the authors. Licensee MDPI, Basel, Switzerland. This article is an open access article distributed under the terms and conditions of the Creative Commons Attribution (CC BY) license (http://creativecommons.org/licenses/by/4.0/). 